the harvesting of wild mushrooms, as well as poisoning, identification, photography, and even spore collection.

Overall, this is an excellent introduction for the mushroom enthusiast to expand his or her knowledge about mushrooms, and it is informative to anyone who has even a remote interest in this subject.

The book would be well placed as a "coffee-table book" thanks to its extensive collection of color prints. Equally, it makes a good reference text, affording the reader access to a broad range of topics related to mushrooms. One drawback is that it does not allow for easy identification of a particular mushroom. This is not aided by the fact that the explanation to the guide's layout is found on page 121. This would have been better placed earlier in the book and probably could be better presented as a chart or table.

This book makes a fine addition to the library of anyone interested in mushrooms. Indeed, just browsing through it is a pleasure.

Gerald Dubowitz, MB, ChB San Francisco, CA, USA

\section{Wolves of the World: Natural History and Conservation}

Todd K. Fuller, PhD

Stillwater, MN: Voyageur Press Inc, 2004

US \$29.95, 132 pages, hardcover

In Wolves of the World: Natural History and Conservation, the author, a professor of Wilderness Ecology at the University of Massachusetts, Amherst, takes a scientific but easily understood approach to introducing wolves to the reader. This is a large-format or "coffeetable" book combining text with over 50 full-page color photographs by a variety of well-known nature photographers.

The beginning chapters are dedicated to the natural history and origins of wolves. Subjects include the taxonomy, morphology, and origin of these animals. This section describes the earliest fossil records of wolves, their physical appearance, and their dramatically changing distribution throughout the world.

The next section explores the behavior and intelligence of wolves. Chapters dedicated to how they communicate, interact with the environment, and what they eat give the reader a better understanding of their complex social structure. The section describes how wolves live and hunt in well-structured social groups. In addition, the chapter about how wolves communicate highlights their intelligence. For example, it is estimated that 6-week-old pups already use 11 different vocal signals.
The final chapters focus on the interaction between wolves and human beings. Wolves are on a short list of species that have a comparable ability to evoke a wide range of emotional response in human beings. To many of us, the wolf is the ultimate symbol of wilderness and freedom. In contrast, to many farmers, ranchers, and hunters, the wolf represents the ultimate threat to livestock and game.

The book describes some of the conservation efforts underway to save wolves. Included is a historical perspective of wolf populations throughout the world that is important to understanding the plight of wolves today. In North America, one of the most successful conservation programs is in Yellowstone National Park. After opening in 1872, the park's policy of "predator control" had completely eliminated wolves by 1926 . After their reintroduction in 1995 and 1996, wolves have flourished in Yellowstone National Park, and today Yellowstone serves as the premier viewing area for wolves in North America.

The photographs in the book are simply beautiful. All are full color, and many are full page. They show wolves living in their natural habitat, hunting, playing, and raising their young. The pictures of wolf pups are particularly evocative.

With its well-written text and beautiful photographs, Wolves of the World: Natural History and Conservation should appeal both to those interested in animal conservation and to anyone who appreciates the beauty and mystique of these magnificent animals.

David A. Townes, MD, MPH

Seattle, WA, USA

\section{The Traveler's Medical Guide, 3rd edition}

Gary R. Fujimoto, MD; Marc R. Robin, ANP; and

Bradford L. Dessery, RN

Brooklyn Center, MN: Prairie Smoke Press, 2003

US $\$ 24.95,490$ pages, softcover

An oddity in travel medicine is that practitioners see travelers before they leave on their trips and then again only should the travelers return home ill. Healthwise, travelers are more or less on their own during their trips, which is the time that they may need the practitioners the most. It is somewhat akin to a surgeon providing pre- and postoperative care but not performing the surgery.

But experience has shown that even with state-of-theart communications it is not particularly helpful for home-based practitioners to try to help someone with a fever in Delhi or chest pain in Barcelona. This dilemma 
is further compounded by the realities that most illnesses and mishaps occur in developing countries, and that in such countries travelers should seek local health care only when absolutely necessary and should take care of as many of their own health issues as possible.

In many developing countries, health care personnel tend to be poorly trained and inadequately equipped and are prone to give injections and prescribe medications for trivial conditions best left untreated, says the World Health Organization. This is done because both the providers and the local people believe that injections are more effective than oral medications and that antibiotics are essential when you are "sick." The option of "doing nothing" and just giving advice does not really exist. "Doing something" is the "art of medicine." And such philosophies are most common in countries where some cases of AIDS and hepatitis B are transmitted by contaminated needles and syringes used by health care personnel, where the overuse of antibiotics is one reason for multidrug-resistant organisms and where a substantial percentage of local medications are counterfeited, adulterated, or outdated. (Previous editions of this guide were titled, Medical Guide for Third World Travelers, perhaps a more apropos and more important title than The Traveler's Medical Guide.)

Another common stumbling block to good medical care overseas is language barriers. The subtleties of sickness are very difficult to convey with a phrase book or even through a translator.

So what are travelers to do when heading for areas where medical care is not up to the standards that the traveler is accustomed to? Obviously, pack a book such as the The Traveler's Medical Guide. This particular book is a good one. It is well written and well organized, has 490 pages, and weighs 15 ounces (just under half a kilogram).

People who would find this guide useful include travelers going to developing countries, expatriates, backpackers and hikers going into the wilderness, and health care professionals who advise such individuals. The quality of the information provided in the book can be attested to because the authors are experienced, knowledgeable, and respected in the field and have forewords by some of the leaders in travel medicine.

Ideally, travelers should acquire this book when they start planning their trip, not on the way to the airport, so to speak, which is the time when many travelers start thinking about health issues. A strong point of this guide is the section on pretrip medical planning. Proper planning helps prevent problems and allows travelers to deal intelligently and optimally with problems should they arise. Proper planning includes obtaining specific travelers' health and accident insurance, getting immunizations, and assembling an individualized medical kitsubjects that are well covered in this book.

Altogether, this guide has about 60 headings and subheadings arranged so that readers can quickly locate the topics that interest them. The section "Diagnosis and Treatment of Medical Disorders" covers the body anatomically and by types of infection, and the "Quick Reference Charts" are arranged by symptoms (eg, itching, vomiting and diarrhea, and cough). The appendix, "Medications and How to Use Them," covers vaccination issues, extended stays, traveling with children, traveling for women, and much more.

Karl Neumann, MD, FAAP Forest Hills, NY, USA 